\title{
Morphometric and morphologic study of foramen ovale in Indian population
}

\author{
Mumal Nagwani Mishra', Kaweri Dande², Dewanshi Mishra ${ }^{3}$, Archana Rani ${ }^{4}$, \\ Madhuresh Kumar ${ }^{5}$
}

${ }^{1}$ Associate Professor, Department of Anatomy, Era's Lucknow Medical College and Hospital, ${ }^{2,3}$ Resident, ${ }^{4}$ Professor,

Department of Anatomy, King George's Medical University, ${ }^{5}$ Intern student, Era's Lucknow Medical College and Hospital

\section{A B S T R A C T}

Background: The floor of middle cranial fossa shows several foramina through which vital neural and vascular structures pass. Thus, the knowledge of normal and variant anatomy of these foramina is important. One such foramen is Foramen ovale which allows the passage of certain important structures. Aims and Objective: This study also aimed to provide a base line data to neurosurgeons for easy and safe approach to middle cranial fossa. Thus, to fulfill the above, the morphometric and morphologic characteristics of the foramen ovale were studied and the observed metric and non-metric parameters were compared with those of previous studies. Materials and Methods: The study has been conducted on 160 adult nonpathological dry human skulls of unknown age and sex. Those parts of broken skulls were included in the study in which the area of Foramen ovale was intact. All the parameters were obtained by one observer only to avoid inter-observer error. The foramen ovale was identified and different metric and non-metric parameters were observed and measured. Results: The most common shape on both sides was noted to be transversely oval. Out of 160 skulls, 2 skulls $(1.25 \%)$ showed accessory FO bilaterally. 4 skulls showed divided FO on left side. Out of 4,2 skulls $(1.25 \%)$ were noted to have bony bar and in 2 skulls $(1.25 \%)$ the main FO were divided by bony plate. Conclusion: The morphologic variations of Foramen Ovale in the form of accessory foramen and presence of bony bar/bony plate are common. This study will provide a baseline data as well as frequency of related variations in our population for a safer approach by the surgeons.

Key words: Foramen ovale; Morphometric study; Morphology

\section{INTRODUCTION}

In the floor of the middle cranial fossa, the sphenoid bone shows numerous openings. These foramina transmit vital neural and vascular structures. Many normal variants of these foramina have been well described in the early anatomic and radiologic literature. Recognition of these variants is important not only for understanding the complex regional neurovascular anatomy but also for distinguishing normal from potentially abnormal structures. ${ }^{1}$ Foramen Ovale is generally 2 to $4 \mathrm{~mm}$ long lying medial to the foramen spinosum and lateral to the foramen lacerum over the greater wing of the sphenoid bone., ${ }^{2,3}$ It transmits the mandibular division of the trigeminal nerve, the lesser petrosal nerve, the accessory meningeal branch of the maxillary artery and an emissary vein which connects the cavernous venous sinus to the pterygoid venous plexus in the infratemporal fossa. ${ }^{4}$

\section{Aims and Objectives}

- To conduct an observational study on the variations of foramen ovale in adult dry human skulls.

- To study the morphometric and morphologic characteristics of the foramen.

- To compare the observed metric and non-metric parameters with those of previous studies.

- To provide a base line data to neurosurgeons for easy and safe approach to middle cranial fossa. 


\section{MATERIALS AND METHODS}

The study has been conducted on 160 adult non-pathological dry human skulls of unknown age and sex. Those parts of broken skulls were included in the study in which the area of Foramen ovale was intact. All the parameters were obtained by one observer only to avoid inter-observer error. The foramen ovale was identified. The following parameters were observed and measured.

1. Presence or absence.

2. Presence of accessory foramen/presence of any variation in the form of bony bar or bony plate in relation to foramen.

3. Shape- Anteroposterior oval/Transversaly oval/ round/slit like/almond/irregular.

4. Maximum antero-posterior and transverse diameters.

Measurements on right and left sides were done from intracranial side. Maximum antero-posterior and transverse diameters were measured by placing a pair of dividers on the margins of the foramen. Descriptive statistics (mean, minimum, maximum and standard deviation) were evaluated for all the parameters collected.

\section{Table 1: Showing frequency of foramen ovale}

\begin{tabular}{|c|c|c|c|c|c|c|c|}
\hline \multicolumn{4}{|c|}{ Right } & \multicolumn{4}{|c|}{ Left } \\
\hline \multicolumn{2}{|c|}{ Absent } & \multicolumn{2}{|c|}{ Present } & \multicolumn{2}{|c|}{ Absent } & \multicolumn{2}{|c|}{ Present } \\
\hline No. & $\%$ & No. & $\%$ & No. & $\%$ & No. & $\%$ \\
\hline 00 & 00 & 160 & 100 & 00 & 00 & 160 & 100 \\
\hline
\end{tabular}

\section{RESULTS}

Table 1 show that none skull was observed with absent FO. All the skulls showed the presence of FO bilaterally. Table 2 shows that the most common shape on both sides was observed as transversely oval (R- 75\%, L- 73.8\%), the next common was anteroposteriorly oval (R- 20\%, L- 21.3\%) and the least common as the circular shape $(5 \%$ on both sides). No other shape was noted (e, g., slit like, almond shaped or irregular). Table 3 shows that on right side, the minimum, maximum and mean TD were $3 \mathrm{~mm}, 9 \mathrm{~mm}$ and $5.95 \pm 1.28 \mathrm{~mm}$ respectively and APD were $1.5 \mathrm{~mm}, 7 \mathrm{~mm}$ and $4.03 \pm 1.27 \mathrm{~mm}$ respectively, while the same diameters on left side were $2.5 \mathrm{~mm}, 9 \mathrm{~mm}$ and $5.88 \pm 1.3 \mathrm{~mm}$ respectively for TD and $2 \mathrm{~mm}, 8 \mathrm{~mm}$ and $4.09 \pm 1.44 \mathrm{~mm}$ respectively for APD.

Table 4 shows that out of 160 skulls, 2 skulls (1.25\%) showed accessory FO bilaterally. Figure 1 is showing the Accessory foramen were present anteromedial to main FO on all 4 sides ( $2 \mathrm{R}$ and $2 \mathrm{~L}$ ). 4 skulls showed divided $\mathrm{FO}$ on left side. Out of 4, 2 skulls $(1.25 \%)$ were noted to have bony bar and in 2 skulls $(1.25 \%)$ the main FO were divided by bony plate (Table 4).(Figure 2).

\section{DISCUSSION}

The knowledge of exact dimensions and location as well as for the presence of extra or accessory FO is necessary for correct approach during invasive surgical

Table 2: Showing frequency of various shapes of foramen ovale

\begin{tabular}{|c|c|c|c|c|c|c|c|c|c|c|c|}
\hline \multicolumn{6}{|c|}{ Right } & \multicolumn{6}{|c|}{ Left } \\
\hline \multicolumn{2}{|c|}{ AP oval } & \multicolumn{2}{|c|}{ TR oval } & \multicolumn{2}{|c|}{ Circular } & \multicolumn{2}{|c|}{ AP oval } & \multicolumn{2}{|c|}{ TR oval } & \multicolumn{2}{|c|}{ Circular } \\
\hline No. & $\%$ & No. & $\%$ & No. & $\%$ & No. & $\%$ & No. & $\%$ & No. & $\%$ \\
\hline 32 & 20 & 120 & 75 & 08 & 05 & 34 & 21.3 & 118 & 73.8 & 08 & 05 \\
\hline
\end{tabular}

Table 3: Showing different diameters of foramen ovale

\begin{tabular}{lcccc}
\hline Measurements $(\mathbf{m m})$ & \multicolumn{2}{c}{ Right } & \multicolumn{3}{c}{ Left } \\
\cline { 2 - 5 } & TD & APD & TD & APD \\
\hline Minimum & 03 & 1.5 & 2.5 & 02 \\
Maximum & 09 & 07 & 09 & 08 \\
Mean \pm SD & $5.95 \pm 1.28$ & $4.03 \pm 1.27$ & $5.88 \pm 1.30$ & $4.09 \pm 1.44$ \\
\hline
\end{tabular}

$\mathrm{TD}=$ Transverse diameter, $\mathrm{APD}=$ Anteroposterior diameter.

\begin{tabular}{|c|c|c|c|c|c|c|}
\hline \multirow[t]{2}{*}{$n=160$} & \multicolumn{3}{|c|}{ Right } & \multicolumn{3}{|c|}{ Left } \\
\hline & Accessory foramen & Bony bar & Bony plate & Accessory foramen & Bony bar & Bony plate \\
\hline No./n & $02 / 160$ & $0 / 160$ & $0 / 160$ & $02 / 160$ & $02 / 160$ & $02 / 160$ \\
\hline$\%$ & 1.25 & 0 & 0 & 1.25 & 1.25 & 1.25 \\
\hline
\end{tabular}




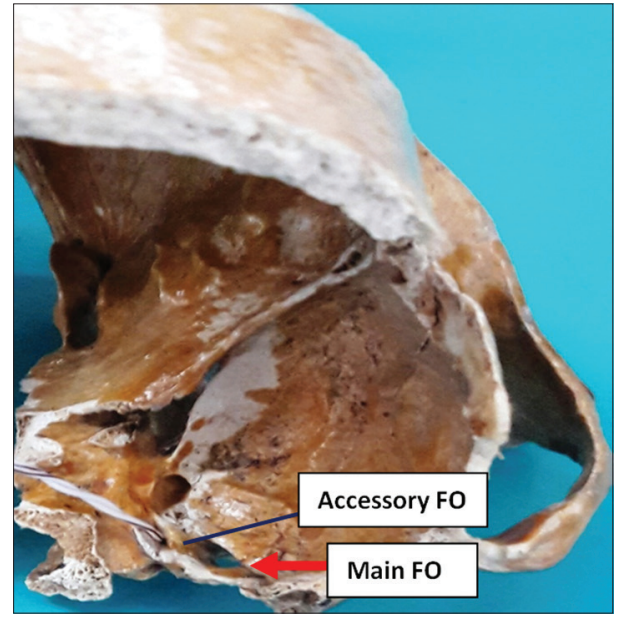

Figure 1: Showing wire in accessory FO

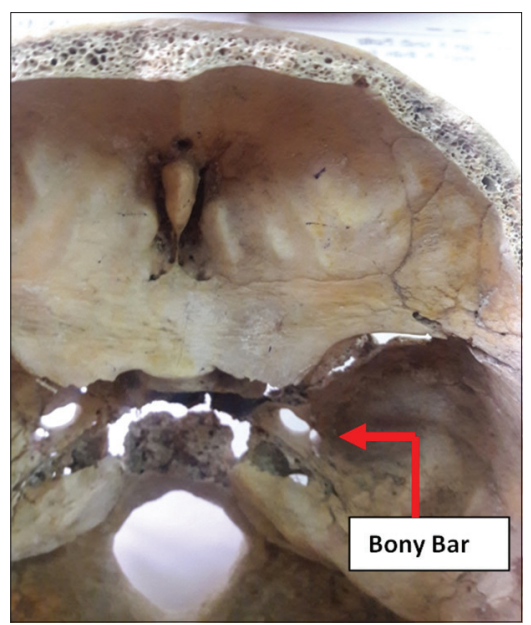

Figure 2: Showing presence of bony bar in FO

and diagnostic procedures. For treatment of Trigeminal Neuralgia, microvascular decompression is done through FO. Electrodes are placed at FO for analysis of EEG for seizures. ${ }^{4}$

Diameters of foramen ovale - In the present study mean length of $\mathrm{FO}$ was $5.9 \mathrm{~mm}$ on right side and $5.8 \mathrm{~mm}$ on left side. Though right foramen ovale was longer than left but no significant difference was observed between the two sides ( $p>0.05)$.In the present study mean length of FO was $5.8 \mathrm{~mm}$ and mean width was $4 \mathrm{~mm}$ considering both sides. Patel, R. et al (2014) reported mean length of foramen ovale as $6.5 \mathrm{~mm}$ and mean width as $3.55 \mathrm{~mm} .^{5}$ A German study ${ }^{6}$ reported average length to be $7.2 \mathrm{~mm}$ and average width as $3.7 \mathrm{~mm}$ in adult skulls. A fluoroscopically-assisted laser targeting of the FO conducted in New York ${ }^{7}$ showed average width on right side as $3.4 \mathrm{~mm}$ and on left side as $3.8 \mathrm{~mm}$. $(4 \mathrm{~mm})$. In the study done by Osunwoke E.A the mean of the lengths of the right foramen ovale was $7.01 \mathrm{~mm}$ while that of the lengths of the left foramen ovale was
$6.89 \mathrm{~mm}$ respectively. The mean of the widths of the right foramen ovale was $3.37 \mathrm{~mm}$ while that of the left foramen ovale was $3.33 \mathrm{~mm}$ He observed no significant difference between the mean of the length and width of the right and left foramen ovale. ${ }^{8}$ In a developmental study conducted in Japan ${ }^{2}$ a maximal length of foramen ovale was observed as $7.48 \mathrm{~mm}$ and minimal length as $4.17 \mathrm{~mm}$ and significant difference between two sides was not observed. ( $9 \mathrm{~mm}$ and $2.5 \mathrm{~mm}$ in present study.) In a study conducted by N. Gupta maximum width of foramen ovale was $5.0 \mathrm{~mm}$ on both right and left sides while minimum width was $1.0 \mathrm{~mm}$ on right side and $2.2 \mathrm{~mm}$ on left side. $(7 / 1.5 \mathrm{~mm}, 8 / 2 \mathrm{~mm}) .{ }^{9}$ Thus, the difference in observations are mainly due to the selection of population belonging to different ethnic groups as well as different sample size. The more accurate results can be projected if the same study will be further carried out on a large sample size.

Shape of foramen ovale- In the present study, the oval shape was noted as the commonest one (95\%) and 5\% of skulls had circular FO. Patel, R. et al $(2014)^{5}$ observed typically oval in $59.5 \%$, round in $27.5 \%$, almond in $12 \%$, and slit like in 1\%.(75\%, 73.8\%). Reymond J. et al $(2005)^{10}$ observed the foramen ovale as always more or less flattened oval. Study conducted by N.Gupta ${ }^{9}$ reported majority of foramen ovale to be oval shape (61.4\%), others were almond shaped, round and slit like.

Bony variations- In the present study, 2 cases of Accessory FO were observed on each side. Septated FO (by bony bar) was noted in 4 cases, all belonging to left side. Patel.R et al, ${ }^{5}$ observed accessory foramina in front of main foramen ovale and presence of septation in 1\% each. Reymond J. et $\mathrm{al}^{10}$ noted a multiple foramen ovale, divided into 2-3 separate components in 9\%. There were different morphological forms of this division. The most frequent was one in which 2-3 foramina were located within one common osseous niche. These foramina were usually the main foramen ovale and accessory foramen/ foramina.

\section{CONCLUSION}

- The morphologic variations of Foramen Ovale in the form of accessory foramen and presence of bony bar/ bony plate are common.

- For the correct approach to FO, the knowledge of basic anatomy, variations and its relation to nearby bony landmarks is necessary.

- This study will provide a baseline data as well as frequency of related variations in our population for a safer approach by the surgeons. 


\section{ACKNOWLEDGEMENT}

Non-teaching staff of department of Anatomy, ELMC\&H and KGMU.

\section{REFERENCES}

1. Bochenek A., Reicher M. Anatomiaczłowieka 1993; 3, Ed. 6. PZWL, Warszawa.

2. Yanagi S. Developmental studies on the foramen rotundum, foramen ovale and foramen spinosum of the human sphenoid bone. Hokkaido Igaku Zasshi 1987; 62(3):485-496.

3. Ginsberg LE, Pruett SW, Chen MY and Elster AD. Skullbase foramina of the middle cranial fossa: reassessment of normal variation with high-resolution CT. Am J Neuroradiol 1994; 15(2):283-291.

4. Susan S. (2008). The Anatomical Basis of Clinical Practice. In: SusanStandring, editor. Gray's Anatomy, $40^{\text {th }}$ ed. London
UK: Elsevier Churchill Livingstone; p.415.

5. Patel R and Mehta CD. Morphometry of foramen ovale at base of skull in Gujrat. Journal of dental and Medical Sciences 2014; 13(6): 26-30

6. Lang J, Rand M and Schafhauser O. Postnatal enlargement of the foramina rotundum, ovale etspinosum and their topographical changes. Anatomischer Anzeiger 1984; 156(5): 351- 387.

7. Landl MK and Grand W. Trigeminal Neuralgia: Fluoroscopically-Assisted Laser Targeting of the Foramen Ovale. Technical Note. Minrad International 2005.

8. Osunwoke EA, Mbadugha CC, Orish CN, Oghenemavwe EL and Ukah CJ. A morphometric study of foramen ovale and foramen spinosum of the human sphenoid bone in the southern Nigerian population. Journal of Applied Biosciences 2009; 26: 16311635.

9. Gupta N, Ray B and Ghosh S. Anatomic characteristics of foramen vesalius. Kathmandu Univ Med J 2005; 3(2): 155-158.

10. Reymond J, Charuta A and Wysocki J. The morphology and morphometry of the foramina of greater wing of human sphenoid bone. Folia Morphol 2005; 64 (3): 183-193.

\footnotetext{
Authors Contribution:

MN- Concept and design of the study, reviewed the literature, manuscript preparation and critical revision of the manuscript; KD- Concept, collected data and review of literature and helped in preparing first draft of manuscript; DM- Concept, collected data and review of literature and helped in preparing first draft of manuscript; AR- Conceptualized study, literature search, statistically analyzed and interpreted, prepared first draft of manuscript and critical revision of the manuscript; MK- Concept of study, collected data and review of study.

Work attributed to:

Department of Anatomy, Era's Lucknow Medical College and Department of Anatomy, King George's Medical University.

Orcid ID:

Dr. Mumal Nagwani Mishra - (D) https://orcid.org/0000-0001-9904-940X

Dr. Kaweri Dande - (1) https://orcid.org/0000-0003-0450-3484

Dr. Dewanshi Mishra - id https://orcid.org/0000-0001-6697-4199

Dr. Archana Rani - (D) https://orcid.org/0000-003-3057-7743

Madhuresh Kumar - (iD https://orcid.org/0000-0002-4740-7823

Source of Support: Nil, Conflict of Interest: None declared.
} 